\title{
APPLICATION OF RESPONSE SURFACE METHODOLOGY FOR OPTIMIZATION OF CADMIUM ADSORPTION IN AN AQUEOUS SOLUTION BY ACTIVATED CARBON PREPARED FROM Bauhinia Purpurea LEAVES
}

\author{
H. Joga Rao ${ }^{1, *}$, P. King ${ }^{2}$ and Y. Prasanna Kumar ${ }^{3}$ \\ ${ }^{1}$ Department of Chemical Engineering, GMR Institute of Technology, Rajam-532127, \\ Andhra Pradesh, India. \\ ${ }^{2}$ Department of Chemical Engineering, Andhra University College of, Engineering, \\ Visakhapatnam-530008, Andhra Pradesh, India. \\ ${ }^{3}$ Principal, Visakha Institute of Engineering and Technology, Visakhapatnam-530027, \\ Andhra Pradesh, India. \\ *E-mail : hjrgmrit@gmail.com
}

\begin{abstract}
An empirical model was developed and validated applying ANOVA analysis incorporating interaction effects of all parameters and optimized using response surface methodology (RSM) for the adsorption of cadmium onto activated carbon prepared from Bauhinia Purpurea leaves. These analyses were performed by means of Fisher's $F$ - test, Student $t$-test and Probability ' $P$ ' $(<0.05)$. For the effect of process parameters, the square $(F=806.731$ and $P=$ $0.000061)$ and linear $(F=8035.63$ and $P=0.000035)$ terms are having a significant effect than interactive $(F=$ 101.578 and $P=1.829998$ ) terms on \% removal of cadmium. The process variables of $X_{1}$ and $X_{4}$ showed the greatest significant positive effect and the other variables of $X_{2}$ and $X_{3}$ are having an insignificant effect on the cadmium adsorption process. All the squared terms, $X_{1}, X_{2}, X_{3}$ and $X_{4}$ shows a significant negative influence on the adsorption of cadmium. The interaction effect between process variables of $\mathrm{X}_{1} \mathrm{X}_{3}(P=0.000808, t=4.5669), \mathrm{X}_{2} \mathrm{X}_{3}(P=$ 0.000018, $t=7.1926)$, were found to be statistically significant and having a positive effect, whereas the combinations of $\mathrm{X}_{1} \mathrm{X}_{2}(t=1.0919, P=0.298219), \mathrm{X}_{1} \mathrm{X}_{4}(P=0.185458, t=-1.4125), \mathrm{X}_{2} \mathrm{X}_{4}(P=0.832451, t=-0.2166)$, $\mathrm{X}_{3} \mathrm{X}_{4}(P=0.513044, t=-0.6759)$ are having an insignificant and a negative effect on the \% removal of cadmium. The optimal values from RSM for cadmium was $\mathrm{pH}\left(X_{1}\right)=6.45, C_{i}\left(X_{2}\right)=3.54 \mathrm{mg} / \mathrm{L}, w\left(X_{3}\right)=0.14 \mathrm{~g}, T\left(X_{4}\right)=$ $313.56 \mathrm{~K}$ and maximum removal efficiency is $87.63 \%$.
\end{abstract}

Keywords: Bauhinia purpurea leaves, Central Composite Design, optimization.

(C) RASĀYAN. All rights reserved

\section{INTRODUCTION}

The presence of heavy metals in the aquatic ecosystem results in a serious threat because of their toxicity, bioaccumulation, and bio-magnifications in the food chain. ${ }^{1-3}$ Industries produce much wastewater and sludge containing heavy metal (Zinc, Copper, Nickel, Lead, Chromium, Cadmium, Mercury, etc.) ions with various concentrations, which are very toxic and carcinogenic to the human and other living organisms ${ }^{4,5}$. The scope of this research work is the optimize the process parameters by using Response Surface Methodology. The main reason for implementing RSM is to evaluate the optimum process conditions for the adsorption or to determine a region that satisfies the operating specifications ${ }^{6}$. Response Surface Methodology is an efficient statistical method to assess the optimum operating conditions of the process or to resolve the range of process parameters that meets the process specifications with a minimum number of experiments as well as to inspect the relationship between one or more response variables and a set of quantitative experimental variables or factors. To provide efficient conditions for the process, RSM consists of design and experiments, response surface modeling through regression and

Rasayan J. Chem., 11(4), 1577-1586(2018) http://dx.doi.org/10.31788/RJC.2018.1144024

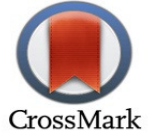


optimization $^{7}$. The application of statistical experimental design technique was adopted in the adsorption process to attaining a high degree of metal removal, closer confirmation of the output response to nominal and target requirements and reduced development time and overall costs ${ }^{8}$.The central composite design was used to optimize cadmium removal by activated carbons prepared from Bauhinia Purpurea leaves in a batch system. It is used to examine the relationship between one or more response variables and a set of quantitative experimental variables or factors. The process optimization of the Cadmium recovery from ACBPL as the adsorbent using adsorption process has not been reported in the literature. Hence the present work intends to assess the effects of variables such as initial cadmium concentration, the weight of the adsorbent, temperature and $\mathrm{pH}$ of the solution to identify the optimum conditions using a central composite design (CCD). Designing of experiment and consistency of variables affecting the system is critical in the optimization process. The conventional optimization is carried out by varying a parameter whilst maintaining all other parameters involved at constant levels. Such methods are simple but do not describe the interaction effects of process variables. Moreover, this method is time consuming and gives low efficiency in optimizing the variables. In addition, the conventional classical method requires a large number of experimental runs to determine the optimum values. RSM is a collection of the statistical and mathematical technique used to develop, improve and optimize different processes. RSM is used to understand the crucial role of the experimental conditions (process parameters), as well as their interactions in a adsorption process ${ }^{9,10}$. It also gives the information about the complete interaction effects of all the process parameters influencing the adsorption process. In the present research work, RSM was adopted to study the influence of various process variables in the adsorption process and to determine the accurate model which in turn is used to get more accurate optimized values.

\section{Materials and Methods}

\section{EXPERIMENTAL}

RSM is one of the relevant techniques of experimental design which is frequently utilized after the essential controllable factors are distinguished and to discover the variable settings that optimize the response. RSM is preferred as it is convenient in making various projections, providing graphical illustrations. Consequently, this technique provides visual elucidation of the practical relations between the response and experimental variables. ${ }^{11,12}$ In numerous chemical, biochemical and bio-environmental processes, RSM has been adapted to analyze, optimize and assess the interactive effects of independent factors. As per the research works conducted, Box and Wilson inspired the use of orthogonal design for evaluating the first-order model ${ }^{13}$. Eminent scientists and engineers have gained proficiency in applying central composite designs (CCDs) and three-level designs by the Box and Behnken for the second-order models ${ }^{14}$. In spite of many available designs available for fitting a second-order model, CCD suggested by Box and Wilson is the most preferred one among all the designs. It consists of factorial points (from a $2^{m}$ design), central points, and axial points. Based on these points, the total number of experiments designed by CCD will be:

$$
N=2^{m}+2 m+k_{o}
$$

Where, $\mathrm{N}$ is the total no. of experiments, $m$ is the no. of the factors studied, and $k_{o}$ is the no. of replicates. Design expert software or Minitab is generally preferred for using CCD under RSM. In this study, statistical software STATISTICA 6.0 (Stat Soft Inc.) is used as an optimization software. The value of $\alpha$ is important to calculate in $\mathrm{CCD}$, as the location of axial points in the experimental domain could be easily determined using the value. The $\alpha$ value determines the design to be applied, whether spherical, orthogonal, rotatable, or face-centered. More accurately, the CCD is made by choosing a value of :

$$
\alpha=\left[2^{\frac{m}{4}}\right]
$$

To study the influence of $\mathrm{pH}$ of the solution (2-8), initial lead concentration in the solution $\left(C_{i}=2-10\right.$ $\mathrm{mg} / \mathrm{L})$, Dosage of adsorbent $(w=0.025-0.15 \mathrm{~g})$ and temperature of the solution $(303-323 \mathrm{~K})$ on the $\%$ removal, a Central Composite Design (CCD) is used to optimize the levels of these variables. Analysis of 
variance (ANOVA) was utilized to test the significance of each term in the equation and the goodness of fit of the regression model. ${ }^{15-17}$

This RSM is applied to gauge the result by contour plots in order to examine the individual and cumulative effects of the variables and the mutual interactions between the variables on the dependent variable.Using the response surface regression procedure of statistical analysis system experimental data obtained was analyzed. The interaction between responses and independent factors was obtained by fitting them into second-order polynomial equation:

$$
Y=\alpha_{o}+\sum_{i=1}^{k} \alpha_{i} x_{i}+\sum_{i=1}^{k} \alpha_{i i} x_{i}^{2}+\sum \sum_{i<j}^{k} \alpha_{i j} x_{i} x_{j}+\epsilon
$$

Where $\mathrm{Y}$ is the response, $\alpha_{0}$ is the constant, $\alpha_{\mathrm{i}}$ is the incline or straight impact of the data element $x_{i}, \alpha_{\mathrm{ii}}$ is the quadratic effect of input factor $x_{\mathrm{i}}, \alpha_{\mathrm{ij}}$ is the linear by linear interaction effect between the input factor $x_{i}$ and $\epsilon$ is the residual term.

\section{RESULTS AND DISCUSSION}

Activated carbon prepared from Bauhinia Purpurea leaves (ACBPL) was used as low-cost adsorbent for removal of cadmium from aqueous solution. Optimization of adsorption process parameters using response surface methodology was also reported in this section.

Table -1: Range of Adsorption Process Parameters covered in the Present Study

\begin{tabular}{c|c|c}
\hline \multirow{2}{*}{$\begin{array}{c}\text { Process parameter } \\
\text { Contact time, } t(\mathrm{~min})\end{array}$} & $\begin{array}{c}\text { Activated Carbon prepared } \\
\text { from Bauhinia Purpurea } \\
\text { leaves }\end{array}$ \\
\cline { 2 - 3 } Cadmium \\
\hline Solution $\mathrm{pH}$ & $\mathrm{M}$ & $\mathrm{Max}$ \\
\hline Initial metal ion concentration of the solution, $C_{i}(m g / L)$ & 2 & 10 \\
\hline The average particle size of the adsorbent, $d(\mu \mathrm{m})$ & 2 & 10 \\
\hline The dosage of the adsorbent, $w(\mathrm{~g})$ & 74 & 177 \\
\hline Temperature, $T(\mathrm{~K})$ & 0.025 & 0.15 \\
\hline
\end{tabular}

Table -2: Experimental Variables and Levels investigated by Central Composite Design

\begin{tabular}{c|cc|c|c|c|c}
\hline \multirow{2}{*}{ Variable } & \multirow{2}{*}{ Process parameter } & -2 & -1 & 0 & 1 & 2 \\
\hline & & 3 & 4 & 5 & 6 & 7 \\
\hline $\mathrm{X}_{1}$ & Solution $\mathrm{pH}$ & 2 & 4 & 6 & 8 & 10 \\
\hline $\mathrm{X}_{2}$ & Initial metal concentration,$C_{i}(\mathrm{mg} / \mathrm{L})$ & 0.05 & 0.075 & 0.1 & 0.125 & 0.15 \\
\hline $\mathrm{X}_{3}$ & Dosage of adsorbent, $w(g)$ & 303 & 308 & 313 & 318 & 323 \\
\hline $\mathrm{X}_{4}$ & Temperature $(\mathrm{K})$ & \multicolumn{4}{c}{ Level of Process parameters } \\
\hline
\end{tabular}

\section{Optimization of Adsorption Process Parameters using Factorial Experimental Design (CCD)}

The response surface methodology is a collection of useful mathematical and statistical technique for analyzing the effects of several independent parameters on the response of interest. Preliminary experimental results indicated that the $\mathrm{pH}\left(\mathrm{X}_{1}\right)$,initial metal concentration $\left(\mathrm{X}_{2}\right)$, adsorbent dosage $\left(\mathrm{X}_{3}\right)$ and temperature of metal solution $\left(X_{4}\right)$ were all the five essential parameters of adsorption studies, significantly affected the percentage of adsorption and metal deposition on activated carbon of Bauhinia Purpurea leaves. Therefore, these parameters were chosen to achieve the optimized conditions for the maximum percentage of adsorption of Cadmium onto activated carbon of Bauhinia Purpurea leaves using response surface methodology. The response was expressed as the percentage of adsorption of Cadmium onto the adsorbent. A CCD with 26 experiments, which includes a 8 cubic point runs, 6 center point runs and 2 axial point runs, was utilized for the optimization of process parameters. For statistical calculations, all independent variables were coded to five levels as $\mathrm{X}_{\mathrm{i}}$ according to the following equation, 
RASĀYAN J. Chem.

Vol. 11 | No. 4 |1577 - 1586| October - December | 2018

$$
X_{i}=\frac{x_{i}-x_{o i}}{\Delta x_{i}}(\mathrm{i}=1,2,3, \ldots \ldots \ldots \ldots . . . .)
$$

Where, $\mathrm{X}_{\mathrm{i}}$ is the dimensionless value of an independent variable, $\mathrm{X}_{\mathrm{i}}$ is the real value of an independent variable, $x_{o i}$ is the real value of the independent variable at the center point, and $\Delta X_{i}$ is the step change. On the basis of preliminary experimental results, it is noted that all the four parameters $\mathrm{pH}$, initial metal ion concentration, the dosage of the adsorbent and temperature significantly affected the adsorption efficiency of Cadmium and metal deposition on the adsorbent. For statistical calculations, all independent variables were coded using Equation (3) as discussed in section (2). Based on the analysis of preliminary experimental results the levels of independent process variables used in a CCD are shown in Table- 1 . The application of RSM yielded the following regression models and the following equation was found to represent the \% removal of cadmium (Y) using activated carbon of Bauhinia Purpurea leaves as an adsorbent.

$$
\begin{aligned}
(Y \%)= & -12587.5+83.9 X_{1}-0.5 X_{2}+813.1 X_{3}+78.7 X_{4}-5.2 X_{1}^{2}-0.7 X_{2}^{2}-2775.3 X_{3}^{2}-0.1 X_{4}^{2}+ \\
& 0.2 X_{1} X_{2}+52.7 X_{1} X_{3}-0.1 X_{1} X_{4}+41.5 X_{2} X_{3}-1.6 X_{3} X_{4}
\end{aligned}
$$

In order to study the combined effect of the factors, experiments were performed for different combinations of the process parameters using statistically designed experiments (Table-2). Apart from the linear effect of the parameters on the adsorption efficiency of cadmium, the RSM also gives insight into the squared and interaction effects of the parameters. These analyses were performed by means of Fisher's $F$ - test and Student $t$-test ${ }^{18}$.The Student $t$-test was used to determine the significance of the regression coefficients of the parameters. In general, the larger the magnitude of $t$ and smaller the value of $P$, the more significant is the corresponding coefficient term. The influence of linear, square and interaction effects of process variables on the adsorption efficiency of cadmium is shown in Table-3. These results were demonstrated from the cadmium adsorption process by means of Fisher's $F$-test and Student $p$-value. For all the parameters, the square model $(F=806.731$ and $P=0.000061)$ and linear $(F=$ 8035.63 and $P=0.000035)$ model terms are having significant effect than interactive $(F=101.578$ and $P$ $=1.829998$ ) model terms of cadmium adsorption process using activated carbon of Bauhinia Purpurea leaves as an adsorbent. Based on $t$-test and $p$-values of the process variables of $X_{1}$ and $X_{4}$ showed the greatest significant positive effect and the other variables of $X_{2}$ and $X_{3}$ (Table-4) are having an insignificant effect on the cadmium adsorption process. All the squared terms, $X_{1}, X_{2}, X_{3}$ and $X_{4}$ shows a significant negative influence on the adsorption of cadmium using activated carbon of Bauhinia Purpurea leaves as an adsorbent. The interaction effect between process variables of $\mathrm{X}_{1} \mathrm{X}_{3}(p=0.000808, t=$ 4.5669), $\mathrm{X}_{2} \mathrm{X}_{3}(p=0.000018, t=7.1926)$, were found to be statistically significant and having positive effect on adsorption efficiency (\%) of cadmium using activated carbon of Bauhinia Purpurea leaves as an adsorbent, whereas the combinations of $\mathrm{X}_{1} \mathrm{X}_{2}(t=1.0919, p=0.298219), \mathrm{X}_{1} \mathrm{X}_{4}(p=0.185458, t=-1.4125)$, $\mathrm{X}_{2} \mathrm{X}_{4}(p=0.832451, t=-0.2166), \mathrm{X}_{3} \mathrm{X}_{4}(p=0.513044, t=-0.6759)$ are having an insignificant effect on the adsorption efficiency of cadmium. The shapes of the surface plots indicate an interaction between the variables. The elliptical shape of the response surface curve indicates good interaction between two variables. It represents the interactive effect of any two variables on the response variable when the remaining variables kept constant. The surface and contour plots (Figs.-2a to 2f) are used to show the pictorial representation of the influence of independent variables and their interaction on the dependent variable. The response surface plots had a clear peak, which indicated that the optimum conditions fall inside the design boundary. The maximum adsorption efficiency of Cadmium is indicated by the surface confined to the smallest curve of the plot with the other variable maintained at hold value. The projection of the surface and contour plots (Figs.-2a and 2b) indicate that the adsorption efficiency increased with increasing temperature and attained maximum efficiency of $60 \%$ at $\mathrm{pH}$ : 6.5 and $\mathrm{T}: 314 \mathrm{~K}$. Similarly, Figs. $-2 \mathrm{~d}$ and $2 \mathrm{f}$ indicate that the adsorption efficiency is highly influenced by the initial concentration $(80$ $\%$ at $2 \mathrm{mg} / \mathrm{L}$ ) and moderately with the dosage of the adsorbent ( $60 \%$ at $0.14 \mathrm{~g}$ of $A C B P L$ ) with increasing temperature. Figs.-2d and $2 \mathrm{e}$ show that the adsorption efficiency increased with an increase in $\mathrm{pH}$ from 4 to 6.5 ; the less removal observed at low $\mathrm{pH}$ may be due to the more availability of $\mathrm{H}^{+}$ion activity 1580

H. Joga Rao et al. 
RASĀYAN J. Chem.

Vol. 11 | No. 4 |1577 - 1586| October - December | 2018

comparable to $\mathrm{Cd}^{+2}$ in the solution. Besides, it was explained that at lower $\mathrm{pH}$ value, the surface of the adsorbent is surrounded by $\mathrm{H}^{+}$ions, thereby preventing the metal ions from approaching the binding sites of the adsorbent. This means that at the higher $\mathrm{H}^{+}$concentration, the repulsion is taking place between the metal and adsorbent and decreased adsorption efficiency. In contrast, as the $\mathrm{pH}$ increases, the adsorbent surface converted as more negatively charged surface and capture the lead ions to increase the adsorption efficiency. However, when the $\mathrm{pH}$ was greater than 6.5, there was a decrease in the adsorption capacity. This may be due to the occurrence of Cadmium precipitation. At this stage there are three species present in solution, $\mathrm{Cd}^{2+}$ in very small quantities, $\mathrm{Cd}(\mathrm{OH})^{+}$and $\mathrm{Cd}(\mathrm{OH})_{2}$ in large quantities. ${ }^{19-22}$ The \% removal of Cadmium increased when the initial concentration was increased from 1 to $3 \mathrm{mg} / \mathrm{L}$ (Figs.-2b, 2d and 2f). Besides, higher initial concentrations of Cadmium to an increase in the affinity of the lead ions towards the active sites. However, a further increase in the initial concentration $(>3 \mathrm{mg} / \mathrm{L})$ resulted in a decrease in the adsorption efficiency of Cadmium. This indicates that the initial Cadmium concentration is an effective parameter to maximize adsorption efficiency. The \% removal of Cadmium increased when the dosage of the adsorbent was increased from 0.05 to $0.15 \mathrm{~g}$ (Figs. $-2 \mathrm{c}$ and $2 \mathrm{f}$ ). This was due to the limited availability of the number of adsorbing species for a relatively larger number of surface sites on the adsorbent at a higher weight. However, a further increase in adsorbent dosage $(>0.14 \mathrm{~g})$ resulted in a decrease in $\%$ removal of Cadmium. These results may be due to the overlapping of the adsorption sites as a result of overcrowding of adsorbent particles. In order to maximize the adsorption efficiency of metals, regression model equations (5) developed by using response surface methodology for the prediction of the effect of process variables on the \% removal of Cadmium was optimized separately. The optimal values from RSM for cadmium was as follows: $\mathrm{pH}=6.45$, initial metal ion concentration $=3.54$ $\mathrm{mg} / \mathrm{L}$, dosage of the adsorbent $=0.14 \mathrm{~g}$, temperature $=313.56$ and maximum removal efficiencies of $87.63 \%$. The optimum values for process variables obtained by using RSM were validated by conducting experiments at these optimum conditions and obtained the maximum \% removal of Cadmium is $85.57 \%$. The above results proved that the statistical experimental design using RSM could be effectively used to optimize various process parameters for improving the adsorption of cadmium onto activated carbon of Bauhinia Purpurea leaves as an adsorbent.

Table - 3: Analysis of Variance (ANOVA) for a response surface quadratic model for removal of Cadmium

\begin{tabular}{|c|c|c|c|c|c|}
\hline Source & $\mathrm{SS}$ & $\mathrm{DF}$ & MS & $\mathrm{F}$ & P $($ Prob $>F)$ \\
\hline Linear & 8035.63 & 4 & 8035.63 & 6034.433 & 0.000035 \\
\hline $\mathrm{X}_{1}$ & 4022.27 & 1 & 4022.27 & 3020.561 & 0.000000 \\
\hline $\mathrm{X}_{2}$ & 2758.89 & 1 & 2758.89 & 2071.821 & 0.000000 \\
\hline $\mathrm{X}_{3}$ & 1195.11 & 1 & 1195.11 & 897.484 & 0.000000 \\
\hline $\mathrm{X}_{4}$ & 59.34 & 1 & 59.34 & 44.567 & 0.000035 \\
\hline Square & 806.731 & 4 & 806.731 & 605.822 & 0.000061 \\
\hline $\mathrm{X}_{1}^{2}$ & 465.338 & 1 & 465.338 & 349.450 & 0.000000 \\
\hline $\mathrm{X}_{2}^{2}$ & 120.235 & 1 & 120.235 & 90.291 & 0.000001 \\
\hline $\mathrm{X}_{3}{ }^{2}$ & 52.517 & 1 & 52.517 & 39.438 & 0.000060 \\
\hline $\mathrm{X}_{4}^{2}$ & 168.641 & 1 & 168.641 & 126.643 & 0.000000 \\
\hline Interaction & 101.578 & 6 & 101.578 & 76.281 & 1.829998 \\
\hline $\mathrm{X}_{1} \mathrm{X}_{2}$ & 1.588 & 1 & 1.588 & 1.192 & 0.298219 \\
\hline $\mathrm{X}_{1} \mathrm{X}_{3}$ & 27.773 & 1 & 27.773 & 20.856 & 0.000808 \\
\hline $\mathrm{X}_{1} \mathrm{X}_{4}$ & 2.657 & 1 & 2.657 & 1.995 & 0.185458 \\
\hline $\mathrm{X}_{2} \mathrm{X}_{3}$ & 68.890 & 1 & 68.890 & 51.734 & 0.000018 \\
\hline $\mathrm{X}_{2} \mathrm{X}_{4}$ & 0.062 & 1 & 0.062 & 0.047 & 0.832451 \\
\hline $\mathrm{X}_{3} \mathrm{X}_{4}$ & 0.608 & 1 & 0.608 & 0.457 & 0.513044 \\
\hline Error & 14.648 & 11 & 1.332 & & \\
\hline Total SS & 8649.094 & 25 & $\mathrm{R}^{2}=.9983$ & \multicolumn{2}{|c|}{$\mathrm{R}^{2}(\operatorname{Adj})=.9961$} \\
\hline
\end{tabular}

DF: degree of freedom; SS: the sum of squares; F: factor F; P: probability. 
RASĀYAN $J$. Chem.

Vol. 11 | No. 4 |1577 - 1586| October - December | 2018

Table-4: Estimated Regression Coefficients and Corresponding $t$ - and $P$-Values for the Adsorption of Cadmium. Adsorption parameter $\quad$ Regression $\quad$ Standard Error t-Value $\quad$ p-Value (Mean value) Coefficient

\begin{tabular}{c|c|c|c|c}
\hline Constant & -12587.5 & 1095.705 & -11.4881 & 0.000000 \\
\hline $\mathrm{X}_{1}$ & 83.9 & 18.328 & 4.5763 & 0.000795 \\
\hline $\mathrm{X}_{2}$ & -0.5 & 9.115 & -0.0514 & $0.959945^{* *}$ \\
\hline $\mathrm{X}_{3}$ & 813.1 & 730.933 & 1.1124 & $0.289673^{* *}$ \\
\hline $\mathrm{X}_{4}$ & 78.7 & 6.928 & 11.3659 & 0.000000 \\
\hline $\mathrm{X}_{1}^{2}$ & -5.2 & 0.276 & -18.6936 & 0.000000 \\
\hline $\mathrm{X}_{2}^{2}$ & -0.7 & 0.069 & -9.5022 & 0.000001 \\
\hline $\mathrm{X}_{3}^{2}$ & -2775.3 & 441.934 & -6.2800 & 0.000060 \\
\hline $\mathrm{X}_{4}{ }^{2}$ & -0.1 & 0.011 & -11.2536 & 0.000000 \\
\hline $\mathrm{X}_{1} \mathrm{X}_{2}$ & 0.2 & 0.144 & 1.0919 & $0.298219^{* *}$ \\
\hline $\mathrm{X}_{1} \mathrm{X}_{3}$ & 52.7 & 11.540 & 4.5669 & 0.000808 \\
\hline $\mathrm{X}_{1} \mathrm{X}_{4}$ & -0.1 & 0.058 & -1.4125 & $0.185458^{* *}$ \\
\hline $\mathrm{X}_{2} \mathrm{X}_{3}$ & 41.5 & 5.770 & 7.1926 & 0.000018 \\
\hline $\mathrm{X}_{2} \mathrm{X}_{4}$ & -0.0 & 0.029 & -0.2166 & $0.832451^{* *}$ \\
\hline $\mathrm{X}_{3} \mathrm{X}_{4}$ & -1.6 & 2.308 & -0.6759 & $0.513044^{* *}$ \\
\hline
\end{tabular}

**insignificant $(P \geq 0.05)$

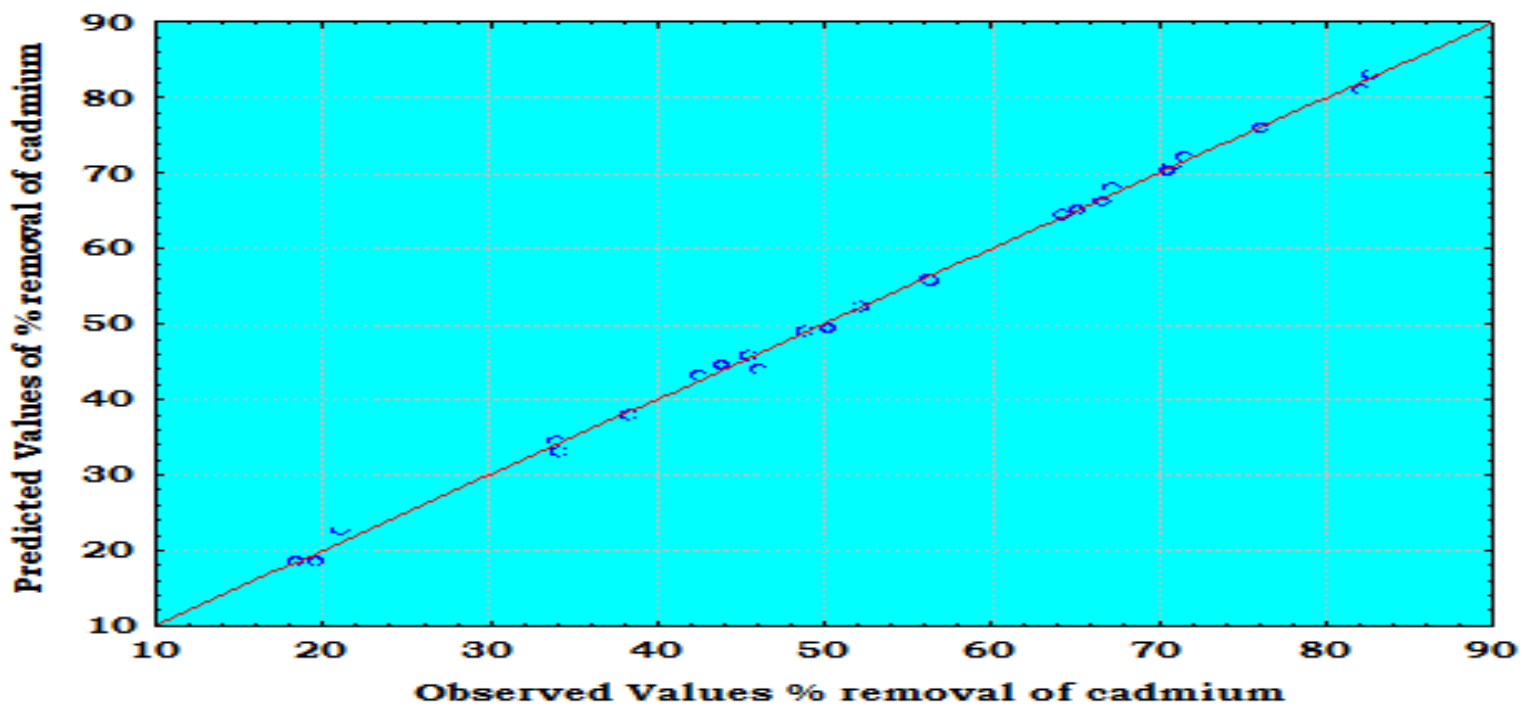

Fig.-1: Correlation Plot of Experimental Values Vs Predicted Values

Table-5: Experimental Design Matrix and Results in the Adsorption of Cadmium

\begin{tabular}{|c|c|c|c|c|c|c|}
\hline \multirow{2}{*}{ Run } & \multirow{2}{*}{$X_{1}$} & \multirow{2}{*}{$X_{2}$} & \multirow{2}{*}{$X_{3}$} & \multirow{2}{*}{$X_{4}$} & \multicolumn{2}{|c|}{$\%$ Removal of Cadmium } \\
\hline & & & & & Observed & Predicted \\
\hline 1 & -1 & -1 & -1 & 1 & 43.77 & 44.64 \\
\hline 2 & -1 & 1 & 1 & 1 & 48.91 & 49.12 \\
\hline 3 & -1 & -1 & 1 & 1 & 52.17 & 52.36 \\
\hline 4 & 0 & 2 & 0 & 0 & 56.21 & 56.06 \\
\hline 5 & -1 & 1 & 1 & -1 & 18.42 & 18.55 \\
\hline 6 & 0 & 0 & 0 & 2 & 21.03 & 22.77 \\
\hline 7 & 2 & 0 & 0 & 0 & 34.04 & 34.56 \\
\hline 8 & 0 & 0 & 0 & -2 & 38.35 & 38.01 \\
\hline 9 & 0 & 0 & 2 & 0 & 67.24 & 68.09 \\
\hline 10 & -1 & 1 & -1 & -1 & 70.78 & 70.93 \\
\hline
\end{tabular}


RASĀYAN $J$. Chem.

Vol. 11 | No. 4 |1577 - 1586| October - December | 2018

\begin{tabular}{c|c|c|c|c|c|c}
\hline 11 & 0 & 0 & 0 & 0 & 82.14 & 81.07 \\
\hline 12 & 1 & -1 & -1 & -1 & 82.76 & 83.14 \\
\hline 13 & 1 & -1 & 1 & 1 & 42.42 & 43.25 \\
\hline 14 & 1 & 1 & -1 & -1 & 45.53 & 45.84 \\
\hline 15 & 0 & -2 & 0 & 0 & 64.24 & 64.54 \\
\hline 16 & -1 & -1 & -1 & -1 & 66.55 & 66.35 \\
\hline 17 & -2 & 0 & 0 & 0 & 19.55 & 18.54 \\
\hline 18 & -1 & -1 & 1 & -1 & 70.52 & 70.32 \\
\hline 19 & 1 & -1 & -1 & 1 & 76.17 & 76.03 \\
\hline 20 & 1 & -1 & 1 & -1 & 34.21 & 33.14 \\
\hline 21 & 0 & 0 & -2 & 0 & 46 & 44.03 \\
\hline 22 & 1 & 1 & 1 & -1 & 71.5 & 72.26 \\
\hline 23 & 1 & 1 & 1 & 1 & 50.24 & 49.51 \\
\hline 24 & 0 & 0 & 0 & 0 & 56.27 & 55.80 \\
\hline 25 & -1 & 1 & -1 & 1 & 65.09 & 65.09 \\
\hline 26 & 1 & 1 & -1 & 1 & 65.09 & 65.09 \\
\hline
\end{tabular}
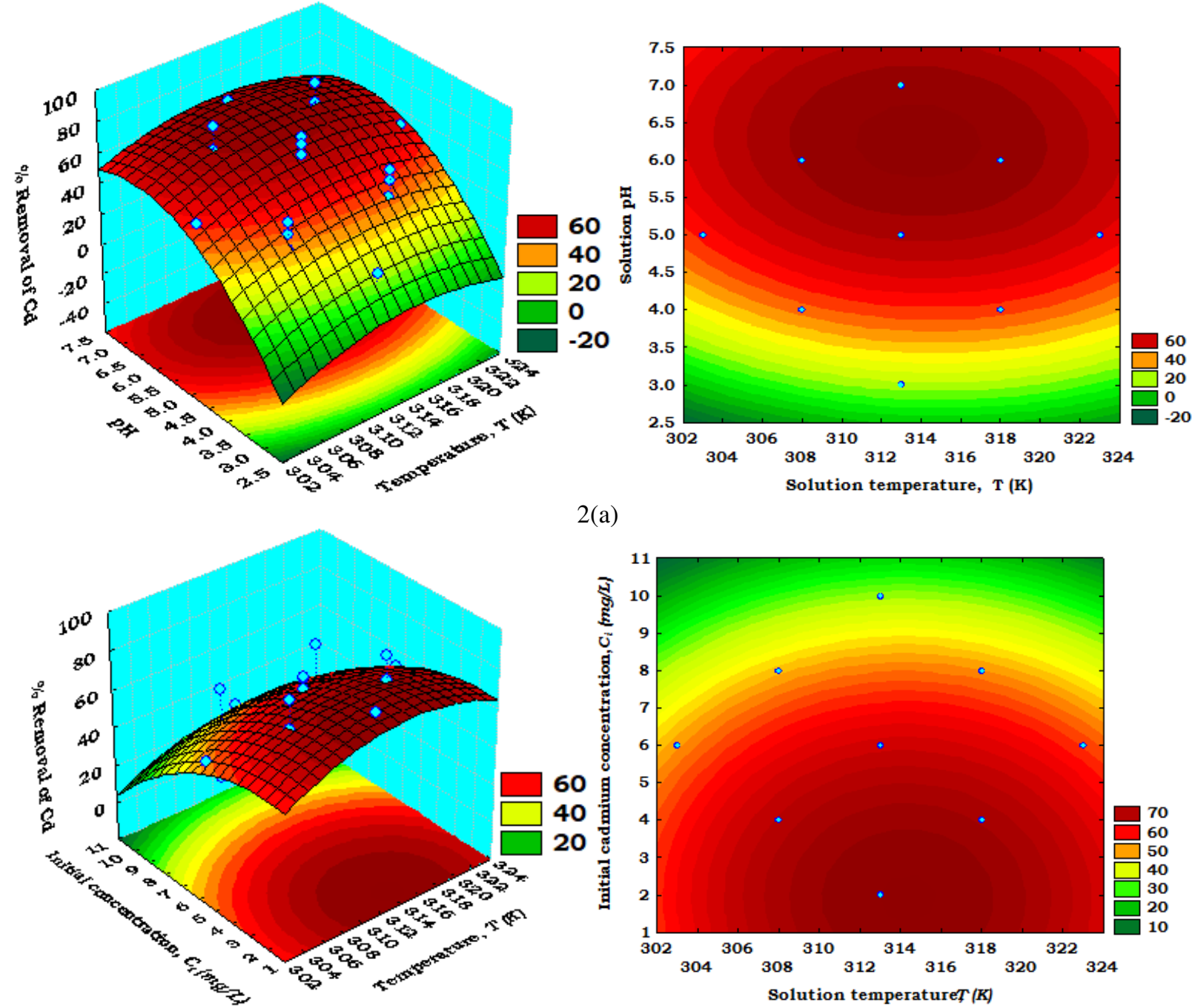

2(a)

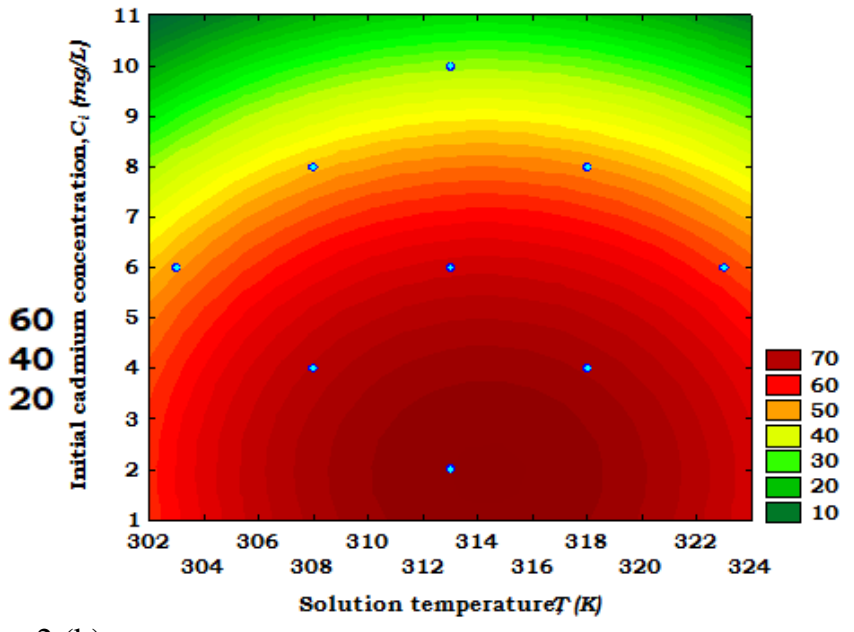

2 (b)

Fig.-2: Response surface and contour plots showing (a) the effect of temperature $\left(\mathrm{X}_{4}\right)$, Solution $\mathrm{pH}\left(\mathrm{X}_{1}\right)$ and their mutual interaction on \% removal of Cadmium, with constant adsorbent dose $\left(\mathrm{X}_{3}\right)$ and initial Cadmium concentration $\left(\mathrm{X}_{2}\right)$; (b) the effect of $\mathrm{X}_{4}, \mathrm{X}_{2}$ and their mutual interaction on \% removal of Cadmium, with constant level of $\mathrm{X}_{1}$ and $\mathrm{X}_{3}$. 
RASĀYAN J. Chem.

Vol. 11 | No. 4 |1577 - 1586| October - December | 2018
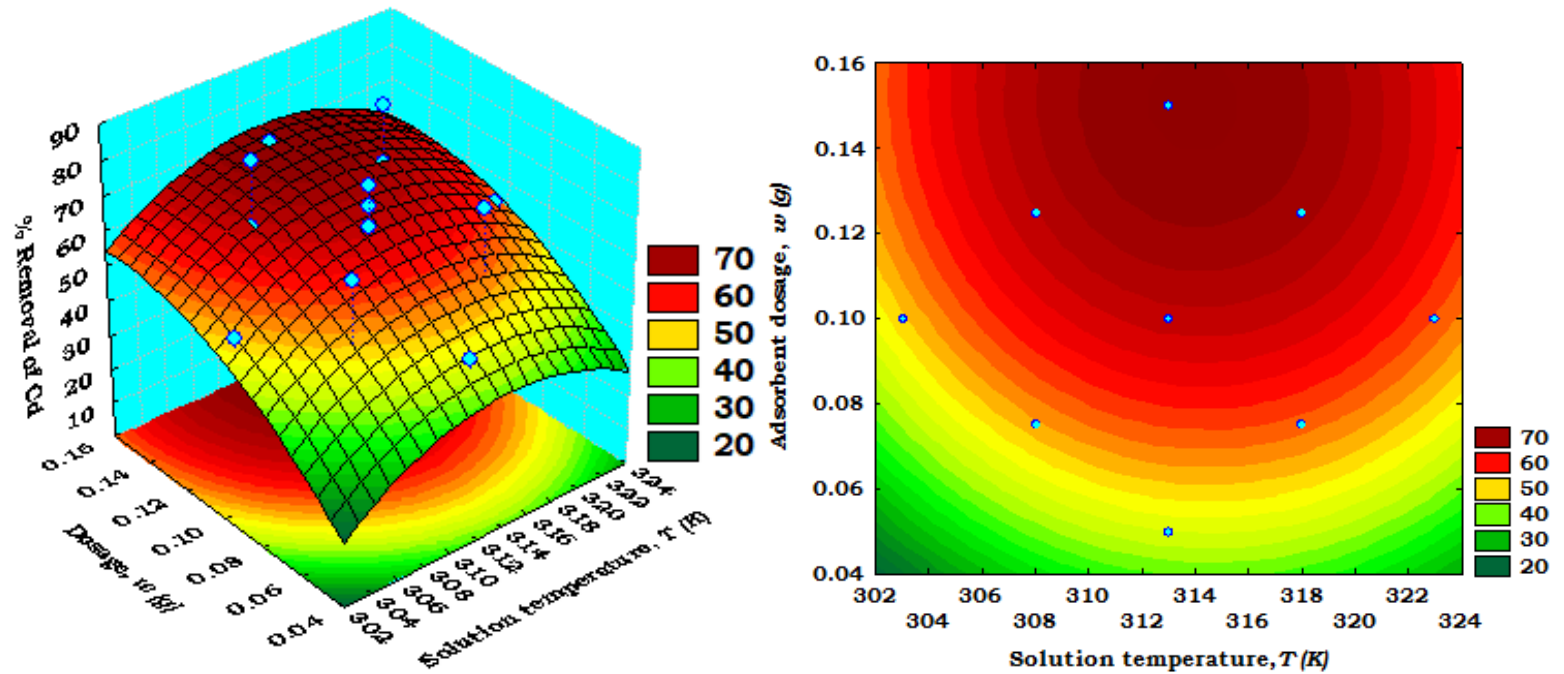

2(c)
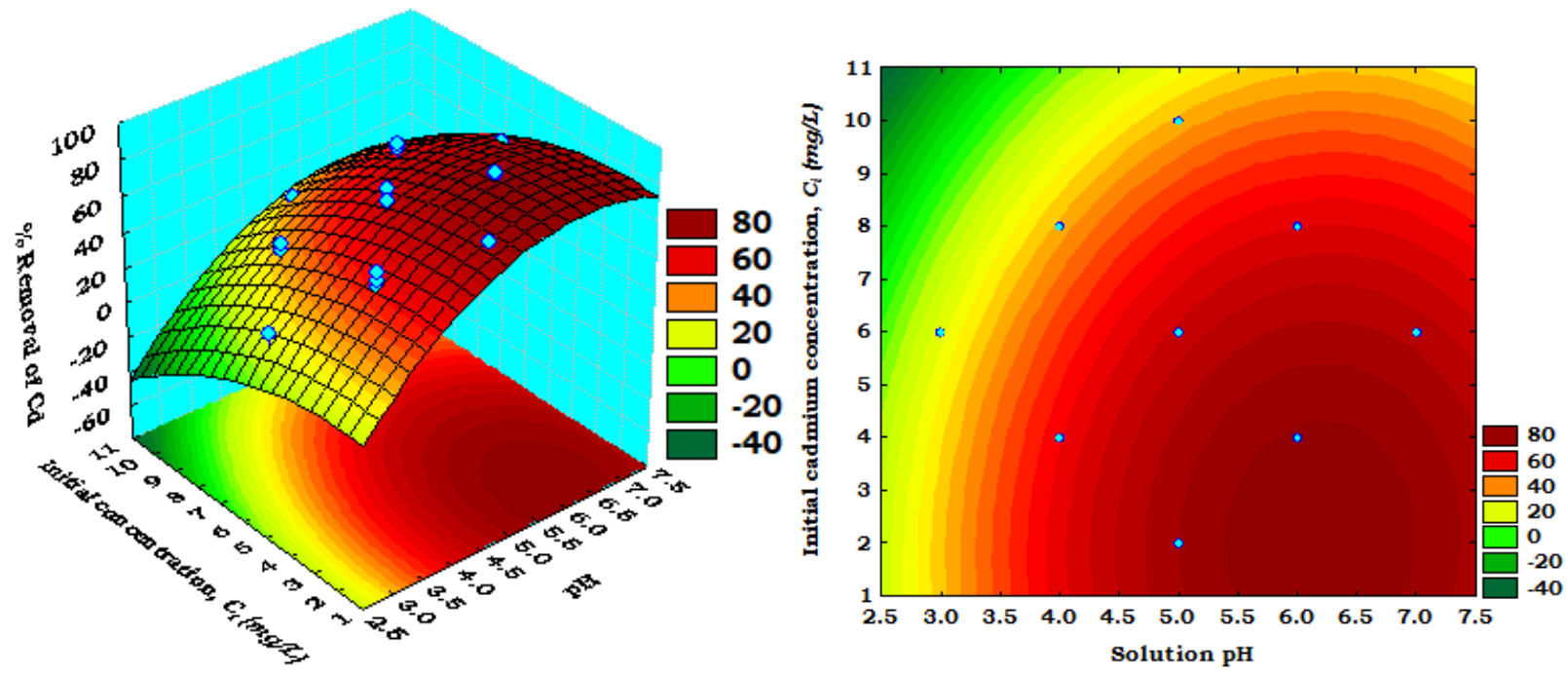

2(d)

Fig.-2: Response surface and contour plots showing (c) the effect of temperature $\left(\mathrm{X}_{4}\right)$, Dosage $\left(\mathrm{X}_{3}\right)$ and their mutual interaction on \% removal of Cadmium, with constant $\mathrm{pH}\left(\mathrm{X}_{1}\right)$ and initial Cadmium concentration $\left(\mathrm{X}_{2}\right)$; (d) the effect of $X_{1}, X_{2}$ and their mutual interaction on \% removal of Cadmium, with constant level of $X_{3}$ and $X_{4}$.
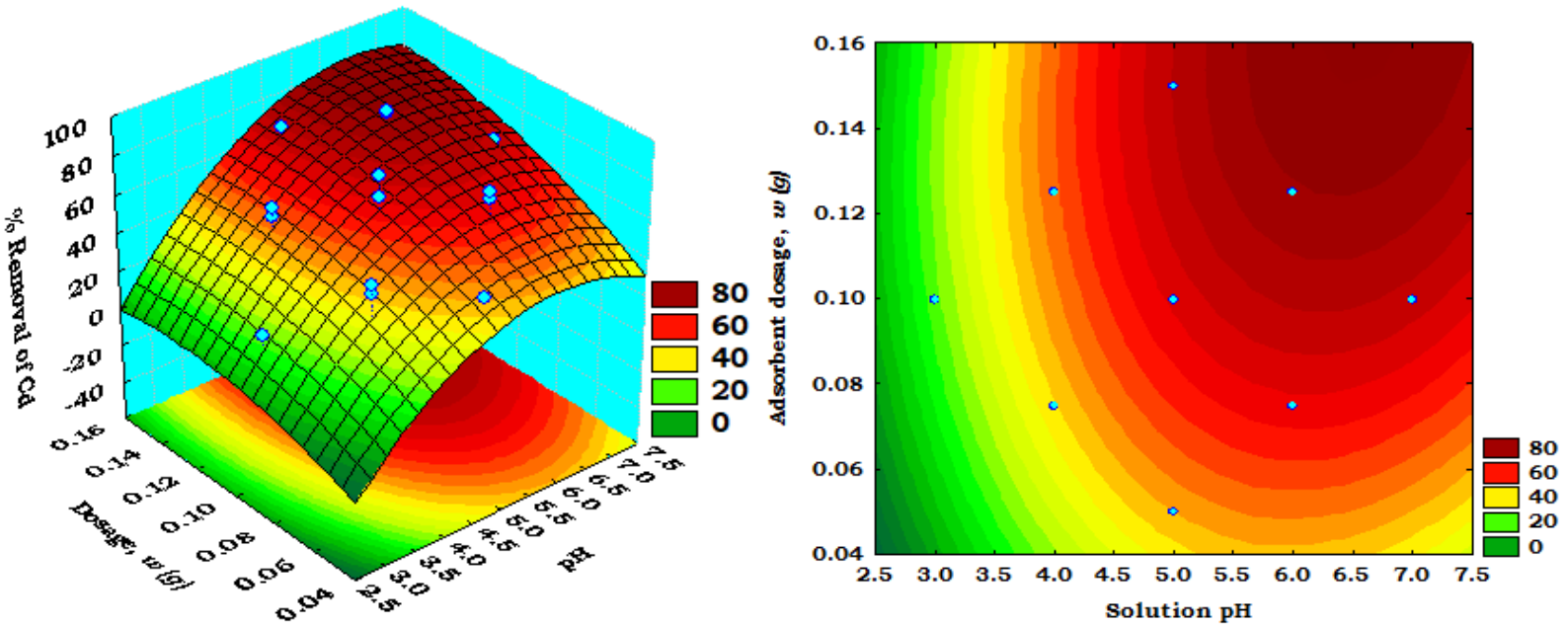

2(e)

1584 
RASĀYAN $J$. Chem.

Vol. 11 | No. 4 |1577 - 1586| October - December | 2018
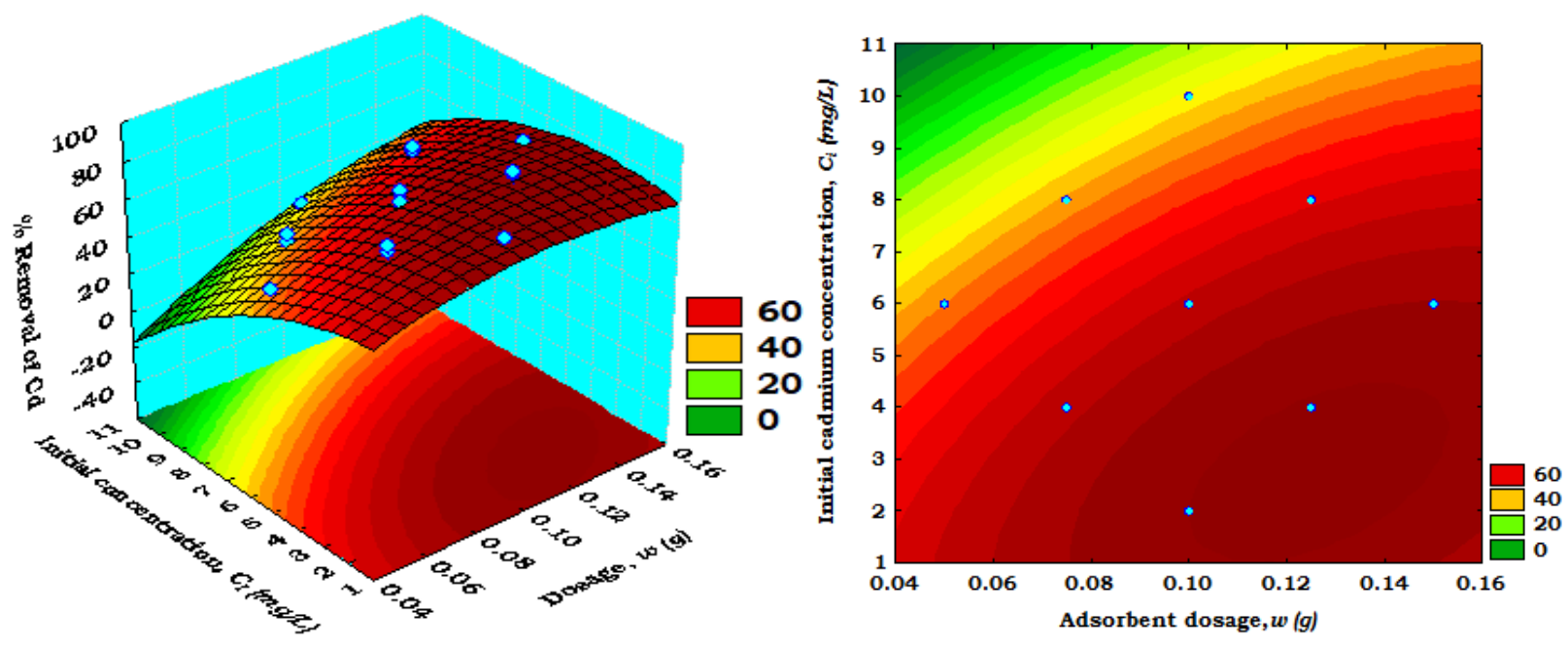

2(f)

Fig.-2: Response surface and contour plots showing (e) the effect of $\mathrm{pH}\left(\mathrm{X}_{1}\right)$, Dosage $\left(\mathrm{X}_{3}\right)$ and their mutual interaction on \% removal of Cadmium, with constant temperature $\left(\mathrm{X}_{4}\right)$ and initial Cadmium concentration $\left(\mathrm{X}_{2}\right)$; ( $\mathrm{f}$ ) the effect of $\mathrm{X}_{2}, \mathrm{X}_{3}$ and their mutual interaction on \% removal of Cadmium, with a constant level of $\mathrm{X}_{1}$ and $\mathrm{X}_{4}$.

Table-6: The Optimal Values of the Process Variables and Responses (\% Removal) of Cadmium.

\begin{tabular}{c|c|c}
\hline & \multicolumn{2}{|c}{ Activated carbon prepared from Bauhinia } \\
Purpurea leaves
\end{tabular}

\section{CONCLUSION}

The effects of various process parameters on \% removal of cadmium and metal uptake of activated carbon of Bauhinia Purpurea leaves as adsorbents were determined using adsorption technique. The following conclusions could be drawn from the present study on the removal cadmium from aqueous solutions using adsorption technique:

- The optimized process variables obtained from the RSM for the adsorption of cadmium onto activated carbon prepared from Bauhinia Purpurea leaves adsorbent was in close agreement with the experimental data.

- The optimal values from RSM for cadmium was as follows: $\mathrm{pH}=6.45$, initial metal ion concentration $=3.54 \mathrm{mg} / \mathrm{L}$, dosage of the adsorbent $=0.14 \mathrm{~g}$, temperature $=313.56$ and maximum removal efficiencies of $87.63 \%$.

- The optimum values for process variables obtained by using RSM were validated by conducting experiments at these optimum conditions and obtained maximum \% removal of Cadmium is $85.57 \%$.

- Second order polynomial equation to represent the adsorption of cadmium onto activated carbon of Bauhinia Purpurea leaves:

$$
\begin{aligned}
\left(Y_{4} \%\right)= & -12587.5+83.9 X_{1}-0.5 X_{2}+813.1 X_{3}+78.7 X_{4}-5.2 X_{1}{ }^{2}-0.7 X_{2}{ }^{2}-2775.3 X_{3}{ }^{2}- \\
& 0.1 X_{4}{ }^{2}+0.2 X_{1} X_{2}+52.7 X_{1} X_{3}-0.1 X_{1} X_{4}+41.5 X_{2} X_{3}-1.6 X_{3} X_{4}
\end{aligned}
$$

- Surface and contour plots were successfully used for the study of evaluation of the effects of two combined process variables on \% removal of metal ions. 
RASĀYAN J. Chem.

Vol. 11 | No. 4 |1577 - 1586| October - December | 2018

\section{REFERENCES}

1. O.S.Amuda, A.A.Giwa and I.A.Bello, Biochem. Eng. J, 36, 174 (2007).

2. M.Momcilovic, M.Purenovic, A.Bojic, A.Zarubica and M.Randelovid, Desalination Water Treat, 276, 53 (2011).

3. T.Bohli, A.Ouederni, N.Fiol and I.Villaescusa, Desalination Water Treat,70,1082 (2013).

4. Deswati , Izzati Rahmi , Hamzar Suyani, Rahmiana Zein and Admin Alif, Rasayan J. Chem., 9(1), 8(2016).

5. H.Joga Rao, P. King, Y. Prasanna Kumar, Rasayan J. Chem., 9(2), 254(2016).

6. M.A. Momod and C.A.Anyakora, Res.J. Environ. Earth Sci., 2, 39(2010).

7. G. Kalyani, Y. Prasanna Kumar, P. King, Rasayan J. Chem., 9(3), 525(2016).

8. Anwar Maruf, Bambang Pramudono, and Nita Aryanti, Rasayan J. Chem., 10(2),414(2017), DOI: $10.7324 /$ RJC.2017.1021667

9. F.Fu, and Q.Wang, J. Environ. Manage.,92, 407(2011).

10. M.M.D.Zulkali, A.L Ahmad and N.H.Norulakmal, Bioresour. Technol., 97, 21(2006).

11. A.Ozer, G.Gurbuz, A.Calimli and B.K.Korbahti,Chem. Eng.J.,146,377(2009).

12. Y.Y.Azila, M.D. Mashitah and S.Bhatia, Bioresour. Technol.,99,8549(2008).

13. G.E.P.Box, and D.W.Behnken, Technometrics.,2,455(1960).

14. S.Rajesh, R.Chadetrika, K.Rajender, B.Kiran, B. Divya, K.Anil, R.B.Narsi and S.Namita, J. Hazard. Mater., 174, 623(2010).

15. G. Nandhavathy, S. Periyar Selvam, M. Mahesh Kumar and E. Rotimi Sadiku, Rasayan J. Chem., 10(2), 542(2017), DOI: 10.7324/RJC.2017.1021724

16. P.Deba sree, M.Umesh and B.Swarup, Journal of Water Process Engineering, 2, 105(2014).

17. A.A.L.Zinatizadeh, M.Pirsaheb, H.Bonakdari and H.Younesi, Waste Manage., 30, 1798 (2010).

18. J.Monika, V.K.Garg and K.Kadirvelu, Bioresour. Technol.,102,600(2011).

19. Deswati, Hamzar Suyani, Izzati Rahmi and Hilfi Pardi, Rasayan J. Chem., 10(4), 1359(2017), DOI: $10.7324 /$ RJC.2017.1041810

20. MunawarIqbal, NidaIqbal, Ijaz Ahmad Bhatti, NaseerAhmad, and Muhammad Zahid, Ecological Engineering., 88, 265(2016).

21. Ivana M Savic, Ivan M Savic, Stanisa T Stojiljkovic and Dragoljub G Gajic, Energy., 77,66(2014).

22. J.Liu , Y.Zhuang, Y.Li ,L. Chen, J.Guo and D.Li, Energy., 60,69(2013).

[RJC-4024/2018] 